This paper focuses on the analysis of the educational method known as "Visual Thinking Strategies" which, after being implemented and evaluated in the United States and countries of East Europe, it is being adopted by many art institutions in Spain and South America. The article goes over the history of this educational method and explores from a critical point of view its advantages and limitations. Furthermore, it critically questions its current implementation and analyzes its theorethical roots, in order to invite the readers to reflect on this educational methodology.

Keywords: museum art education, constructivism, educational methodology. 


\section{Replanteando las estrategias de pensamiento visual: un método controvertido para la educación en museos}

Eneritz

LÓPEZ

Magali

KIVATINETZ

Este artigo constitui uma análise do método educativo conhecido como "Estratégias de Pensamento Visual" que, após haver sido implementado e avaliado em Estados Unidos e países de Europa do Este, está sendo adotado em numerosos centros de arte de Espanha e Sudamérica. O texto apresenta a história deste método educativo analisando críticamente suas vantagens e limitações. Além disso, problematiza sua implementação e revisa suas raízes teóricas, com o objetivo de convidar os leitores a refletirem sobre esta metodologia educativa.

Palavras-chave: museu, ensino de Arte, constructivistmo, metodologia educativa. 


\section{Introducción}

En el contexto en el que vivimos, caracterizado por la inmediatez de las comunicaciones, la complejidad y la incertidumbre, los museos necesitan estar alerta ante la tentación de actuar como instituciones estáticas y cerradas. Ahora al espacio museístico se le pide ser un campo para la problematización y el cuestionamiento, la ruptura y el cambio (ROBERTS, 1997). En la actualidad los museos necesitan implicarse con la sociedad y por ello, han de enfocarse hacia diferentes públicos y trabajar de manera que todos los visitantes puedan encontrar en ellos no sólo un lugar para el disfrute estético, sino también un hueco donde aprender sobre sí mismos, sobre los demás y donde se les autorice a generar e intercambiar visiones críticas y contrahegemónicas (PADRÓ, 2005). Los nuevos planteamientos para la educación artística en museos que se están introduciendo en los últimos años se deben en parte a un creciente interés por encontrar alternativas a la educación tradicional -basada en la simple transmisión de información-, y por ir más allá de la idea de educación como comunicación tan vinculada a la noción de museo instructor. En este contexto de tránsito y replanteamiento, aparecen métodos como el Visual Thinking Strategies (V.T.S.) que, debido a que su principal propuesta educativa es el diálogo, se presenta para los museos como una buena alternativa a los programas educativos tradicionales.

En este artículo exploraremos específicamente el caso de este método educativo, también conocido en su origen como Visual Thinking Currículum (V.T.C.), que ha ido mutando sus acepciones para adaptarse a progresivos cuestionamientos y replanteamientos ${ }^{1}$. Este método se considera actualmente innovador en España y países de latinoamérica, aunque tiene larga tradición de implementación y evaluación en Estados Unidos y países del este de Europa.

Uno de los atractivos principales que tiene V.T.S. para los museos es que solventa, en cierta medida, su preocupación por la educación. Esto se debe a que se presenta como una propuesta dinámica y como una "filosofía" educativa lista para ser implementada en la institución, ya que viene acompañada 
Replanteando las estrategias de pensamiento visual: un método controvertido para la educación en museos

-no sólo del prestigio de la institución en la que inicialmente se originó (el Museum of Modern Art de Nueva York)-, sino también de unas instrucciones que, de seguirlas con fidelidad, garantizan su eficacia. Por ello, V.T.S. encaja muy bien con las expectativas del museo, a pesar de no ser más que el empaquetamiento de unas ideas teóricas que hoy se encuentran en revisión, junto con las indicaciones pertinentes para llevarlo a la práctica en las salas del museo. En este sentido, no debemos pasar por alto la disociación general de tradición teórica sobre educación museística en Latinoamérica, aspecto que permite que los museos se vean sacudidos y cegados por este tipo de ideas que provienen del extranjero, especialmente de Estados Unidos. Estas ideas -basadas en investigaciones desde otros contextos y vinculadas con valores culturales e históricos específicos- son muchas veces adoptadas sin ser cuestionadas y sin ser adaptadas a cada contexto y necesidades. ${ }^{2}$

Este texto está inspirado precisamente en la observación de cómo ha sido implementado V.T.S. en España y en el diálogo con educadores de museos que lo utilizan en su práctica diaria. Además, lo que nos mueve a escribir este artículo es el hecho de haber percibido que se está realizando en distintos países una intensa propaganda sobre este método. Esta publicidad se ha visto acompañada de un creciente interés por adoptarlo en numerosos museos (explícitamente o dándole otro nombre) sin reflexionar sobre cómo podría integrarse en el entorno, y sin tener en cuenta que la educación museística no consiste en la adopción de modelos como si de aplicación de fórmulas se tratara. Para contribuir a la necesaria problematización de las propuestas educativas para los museos, a lo largo de este artículo analizaremos desde varios ángulos este método educativo.

Partiendo de que los museos no son espacios neutrales de representación objetiva de hechos indiscutibles, ya que los valores culturales, sociales y políticos siempre están implicados en las exposiciones (MACDONALD, 1998), apostamos por una educación museística basada en la pregunta, la indagación y preocupada por difundir una nueva noción de museo como zona de controversia y contestación (PADRÓ, 2005). En esta 
línea, el planteamiento crítico desde el que abordamos V.T.S. nos conduce a desvelar sus bases y fundamentaciones, que consideramos alejadas de la educación transmisora en su forma pero no en el fondo. Con ello, queremos introducir una perspectiva alternativa a la que ofrece como predominante este método, para invitar tanto a responsables de departamentos de educación, como a educadores de sala, maestros y profesores a reflexionar sobre esta propuesta.

\section{Buceando en los orígenes del método}

Para contextualizar la corriente en la que se enmarca V.T.S. y ver sus contribuciones en la educación artística en los años 80, haremos un breve recorrido por su historia. En un principio, este método fue propuesto por el MoMA de Nueva York, gracias a las ideas de la psicóloga cognitiva Abigail Housen -dedicada a estudiar en desarrollo del pensamiento estético- y al entonces responsable de educación de este museo, Philip Yenawine. En 1988 se asociaron firmando un contrato dirigido a la creación de programas para estudiantes y profesores visitantes del MoMA. A partir de 1991 comenzaron a ensayar maneras de organizar sus hallazgos en base a un método secuencial que posibilitara a los profesores llevar a cabo discusiones sobre obras de arte con sus estudiantes ${ }^{3}$. En este momento se unieron con el Bard College, el Institute of Contemporary Art en Boston, y el Boston Museum of Fine Arts para producir el primer boceto de lo que sería después el "Visual Thinking Strategies". Mientras tanto, Housen dejó su puesto en el Mass College of Art y Yenawine cesó de su cargo en el MoMA. Posteriormente, en 1995, formaron una consultora educativa llamada Development Through Art, Inc. (D'Art) para continuar su trabajo de diseminación del programa que habían ensayado en el MoMA. Paralelamente constituyen la "Visual Understanding in Education" (V.U.E.), una organización sin fines de lucro, cuya finalidad es extender la investigación en educación basada en el desarrollo desde un sentido cognitivo y evolucionista. Desde 1994 V.T.S. se empieza a implementar en escuelas de Europa del Este y Rusia y, a partir de 1998, inician la publicación de libros de es- 
Replanteando las estrategias de pensamiento visual: un método controvertido para la educación en museos

trategias educativas que ponen en práctica en diversos centros de Estados Unidos (VUE, 2001a).

Después de años de estudio, Housen demostró que la práctica de V.T.S. produce un crecimiento en el pensamiento puramente estético y contemplativo, así como la mejora de otras habilidades cognitivas en un periodo corto de tiempo. Concretamente, esto se logra observando, especulando y razonando en base a evidencias. Esta concepción parte de que el aprendizaje secuencial puede ser fácil, rápido y llevar a resultados espectaculares, sirviendo de base a una noción de educación artística que pretende un resultado inmediato y unívoco, más que una aproximación dialógica, reflexiva y divergente.

En resumen, a pesar de que las originarias ideas de Housen hayan estado siempre presentes, este método, como ya hemos mencionado, ha pasado por diversas metamorfosis, adoptando en cada una de ellas un nombre distinto: V.T.C., V.T.S., Pensamiento Visual, entre otras denominaciones. Esto nos hace ver que a pesar de que se cambie el formato de presentación, las pautas del método están presentes en todas la reinterpretaciones. ${ }^{4}$

\section{Poniendo el zoom en el contexto}

El "Visual Thinking Curriculum", tal y como fue concebido y desarrollado por Housen y Yenawine, se podría asociar con el constructivismo piagetiano, ya que es un método que no presta atención a los contenidos (lo que se aprende), sino sobre todo a los procesos del funcionamiento cognitivo (COLL y GÓMEZ, 1995). En este sentido, es importante recordar que las aportaciones de Jean Piaget fueron fundamentales para la elaboración de una concepción constructivista en el ámbito educativo, ya que contestó al empirismo y al asociacionismo -teorías imperantes en la primera mitad del siglo XX-con el constructivismo, argumentando que el sujeto es activo e interpreta la información del entorno ${ }^{5}$. Esto significa que el conocimiento nuevo se genera a partir del previo porque construir conocimiento incluye un proceso de acomodación de lo nuevo a lo existente, que puede terminar o no por asimilarse. "Una de 
las características de esta perspectiva cognitivista (...) es que la progresión de la inteligencia se vincula al concepto de estadio o etapa"; en otras palabras, para Piaget, la inteligencia atraviesa fases cualitativamente distintas ${ }^{6}$. Sin embargo, "en los años setenta esta forma de concebir el desarrollo intelectual entra en crisis y la caracterización de los estadios pierde su carácter estable, progresivo e intelectual" (AGIRRE, 2000, p. 55).

En suma, según Piaget y sus seguidores, el proceso de construcción del conocimiento es sobre todo de orden interno e individual. Entonces, a la hora de acercarnos a métodos educativos elaborados desde esta postura teórica, como V.T.S., podemos encontrarnos con varios inconvenientes: en primer lugar, la enseñanza que se plantea prioriza que los educandos construyan estructuras de pensamiento que, supuestamente, les permitirán comprender todo tipo de contenidos. En segundo lugar, el conocimiento se construye a través de un proceso de descubrimiento autónomo, derivado de la relación de cada sujeto epistemológico con el entorno inmediato, sin prestar atención a la interacción social. Así, se da a entender que los individuos generan conocimientos desde sí mismos, olvidándose de los factores externos que influyen esta construcción.

De este modo, uno de los principales problemas que presenta V.T.S. es que no considera el componente sociocultural y contextual de la construcción del conocimiento, obviando también que éste es mediado por otros factores, como las relaciones de poder constituidas históricamente. No debemos olvidar que los hechos, los conocimientos, los saberes nunca son neutrales ni objetivos, sino que están producidos e incluidos en contextos de relaciones sociales (ROGERS, 2005, citado en HERNÁNDEZ, 2006). Por ello, una crítica fundamental a este método es que pasa por alto que cualquier conocimiento está inevitablemente ligado a contextos y a las circunstancias biográficas de cada uno, ejes del constructivismo crítico $^{7}$. Esto quiere decir que se ignora que nuestros conocimientos se producen en interrelación con los ambientes en los que se usan, y que los aspectos cognitivos, emocionales y sociales forman parte de cómo somos producidos como sujetos. En relación a esta idea, ya desde principios del siglo XX, la voz de Lev S. 
Replanteando las estrategias de pensamiento visual: un método controvertido para la educación en museos

Vygotsky puso de relieve que "las posibilidades de aprendizaje guardan estrecha relación con el nivel de desarrollo alcanzado y subrayan, en consecuencia, el decisivo papel que el entorno tiene en este proceso de construcción del conocimiento" (AGIRRE, 2000, p. 67). Por ello, una de sus contribuciones esenciales -que métodos como V.T.S. no tienen en cuenta- es la de concebir al sujeto como un ser eminentemente social y al conocimiento mismo como un producto social.

Por otra parte, V.T.S. da más importancia al hecho de establecer un diálogo que a los propios contenidos del mismo. El énfasis del método reside en la forma de llegar al mensaje preestablecido -vinculado a la meta de progresar de un estadio a otro-, y no de prestar atención al aprendizaje que los participantes puedan obtener. Es decir, no se repara en los contenidos (alternativos, paralelos, divergentes) sino en la forma en la que son transmitidos aquellos que se adaptan a la concepción del educador que sigue el V.T.S.

Habrá momentos en que [el profesor] piense que un comentario está equivocado, pero los conceptos de correcto/incorrecto aquí no son válidos. Lo que importa es que los alumnos piensen. Es mejor [no] corregir ni apostillar (VUE, 2001c).

(...) aceptar cada comentario de un modo imparcial. Recuerda que este proceso no está dirigido a conseguir respuestas correctas sino a establecer unas pautas útiles para pensar (VUE, 2001d).

A pesar de que siempre se establece un diálogo entre el educador y su grupo de visitantes, este diálogo utiliza normalmente la "vía socrática", que consiste en poner a los participantes en una situación argumentativa no para aprender cómo pensar por ellos mismos, sino para llegar al lugar en el que el educador estaba inicialmente, es decir, para que consigan aprender lo que el educador tenía previsto desde el principio. Por ello, podemos decir que se trata de un proceso de enseñanza tradicional que concibe que los estudiantes o visitantes aprenderán pensando o actuando del modo en el que el educador les guía. Esto no permite a los participantes abrir posibilidades de divergencia ni hacer conexiones alternativas, 
convirtiendo el proceso de razonamiento en un simulacro de lo que el pensamiento independiente y personal podría llegar a ser (HERNÁNDEZ, 2006). De este modo, la diferencia esencial entre un método de estas características y la educación museística transmisora es su forma pero no el fondo, ya que se sigue partiendo de unos contenidos fijos que los participantes deben aprender.

\section{Releyendo la receta de V.T.S.}

Retomando los orígenes de este método, vemos que el proyecto inicial Ilamado "Visual Thinking Curriculum" es fruto de una revisión constructivista de la perspectiva del arte para la comprensión (art for understanding) impulsado por el grupo Zero de Harvard. Partiendo de una misma base teórica y de problemáticas parecidas vinculadas a la apreciación estética, y casi en paralelo con Housen, Michael Parsons desarrolla, a partir de las ideas de Kohlberg, una metodología similar a la de su colega aunque poniendo el acento en el juicio estético del arte, en vez de en las formas de comprensión. De cualquier modo, la propuesta de Parsons tiene mucho en común con la teoría del desarrollo cognitivo de Piaget, aunque sostiene que aprender arte es sólo una cuestión estética, estableciendo que su significado es distinto del correspondiente a las ciencias o a la moral (PARSONS, 2002).

Un problema que tiene este modelo de interpretación, es que utiliza un marco de referencia estética de base formalista (HERNÁNDEZ, 2000); es decir, que únicamente tiene en cuenta el análisis formal de la obra de arte, sin atender a la incidencia del contexto cultural en los significados estéticos y en los procesos psicológicos. Además, la noción de "estadio de desarrollo" de Piaget difiere de la de Parsons en que la entiende en etapas evolutivo/cognitivas y ve los estadios como agrupaciones de ideas y no como logros de las personas, evitando además cualquier identificación de los estadios con el desarrollo cronológico (MORALES, 2001).

De este modo, Parsons establece cinco estadios del desarrollo del juicio estético que se suceden secuencialmente, de for- 
Replanteando las estrategias de pensamiento visual: un método controvertido para la educación en museos

ma que cada estadio implica una elaboración más compleja que el anterior en los aspectos que considera que están presentes en la respuesta estética (PARSONS, 2002). "La estructuración de estos estadios refleja una evolución que va desde la dependencia en relación con lo que se aprecia en cada obra, hasta la autonomía interpretativa con respecto a ella" (HERNÁNDEZ, 2000, p. 121). Se parte de una visión de progresión donde se considera que el final es la autonomía en vez de pensar que en las artes la ambigüedad, las múltiples versiones e interpretaciones no sólo dependen de la autonomía a la que el espectador llegue, sino que hay que tener en cuenta las cuestiones que la misma obra pueda generar en el observador.

Autores como Hargreaves (1991) argumentan que la teoría de Parsons tiene puntos flojos tales como que se limita al arte visual; que todas las obras que se utilizan en su experimento son propias de las "bellas artes"; y que su método de entrevistas semiestructuradas ofrece desventajas de rigor experimental. A pesar de ello, el estudio de Parsons tiene el mérito de haber acercado el tema del conocimiento estético y artístico a las investigaciones que desde la psicología del desarrollo de tendencia cognitiva comienzan a realizarse en Estados Unidos en los años 70. "Además, ha permitido elaboraciones posteriores que han introducido nuevos criterios de ordenación de las apreciaciones sobre las obras de arte. Una de estas revisiones ha sido el estudio dirigido por Housen et al." (HERNÁNDEZ, 2000, p. 122). En este caso, los estadios hacen referencia al "tipo" de construcción de sentido, o de dotación de significado de cada sujeto, en un recorrido que va desde la narración, basada en preferencias individuales, hasta la actividad reconstructiva. ${ }^{8}$

En síntesis, la propuesta "Visual Thinking Curriculum" permitió "ordenar las apreciaciones de los individuos en torno a las obras de arte, ejemplo de cómo la psicología del desarrollo de orientación cognitiva -a la que se adscribe Housen-, ha abordado su relación con el conocimiento artístico y estético" (HERNÁNDEZ, 2000, p. 123). Este método educativo está vinculado teóricamente a la noción de desarrollo estético progresivo y se enmarca dentro de la psicología evolutiva, manteniendo 
una concepción del aprendizaje como un camino de progreso, haciendo pervivir así una noción moderna del conocimiento.

Siguiendo esta tendencia, se cree que las "Estrategias de Pensamiento Visual" incrementan en gran medida la capacidad de los estudiantes de apreciar el arte, extendiéndose a sus habilidades para hacer arte, respondiendo así al principal interés de los profesores en las escuelas ${ }^{9}$. De este modo V.T.S. ayuda a los especialistas en la tarea de desarrollar la alfabetización visual entre los estudiantes y llegar así a los estándares de la educación artística. Este método educativo constructivista partía de la idea de usar el arte para enseñar a pensar, a desarrollar habilidades comunicativas y para alfabetizar visualmente a niños y jóvenes. Esta noción de "alfabetización visual" está relacionada con la idea del "arte como lenguaje", concepción que lleva a pensar que una imagen se puede leer como si de un texto se tratase. $^{10}$

En este sentido, al V.T.S. le corresponde enseñar a leer la obra de arte. Si no aprendemos a leer, si no damos este primer paso, que es fundamental, nunca podremos desarrollar nuestras capacidades como espectador y como interesados en arte (YENAWINE, 2001).

Sin embargo, consideramos que aunque una imagen contenga códigos, no es un código en sí misma; por lo tanto, al no ser solamente un sistema de signos, no se puede articular como un lenguaje y, consecuentemente, no se puede leer de la misma forma que un texto.

Por otro lado, según los defensores de V.T.S., el crecimiento y desarrollo mental es estimulado de tres modos: mirando detenidamente las obras de arte incrementando progresivamente su complejidad, respondiendo a preguntas basadas en la percepción visual y el desarrollo, y participando en discusiones grupales cuidadosamente coordinadas por educadores. Así, durante cada sesión, utilizando las "Estrategias de Pensamiento Visual" se pretende que cada estudiante pueda señalar lo que ve en la obra de arte que está observando y expresar su opinión sobre ella, argumentando sus interpretaciones. De este modo, los participantes son conscientes de que sus ideas se escuchan y se valoran, comprobando que cada comentario contribuye al pro- 
Replanteando las estrategias de pensamiento visual: un método controvertido para la educación en museos

ceso del grupo en su búsqueda de los diversos significados de la obra de arte (VUE, 2001c).

\section{Superando una educación transmisora}

Una vez presentado el método y problematizados sus fundamentos, destacaremos a continuación sus ventajas, y más adelante, plantearemos algunos de sus inconvenientes. La adopción de V.T.S. por parte de numerosos museos se puede explicar por sus marcados beneficios y avances respecto a la educación transmisora imperante, ya que no toma como punto de partida la idea de un educador transmisor que comunica el discurso del museo al público, sino que propone al educador como un mediador, un facilitador que, a través del diálogo, estimula en los participantes la capacidad de observación y de reflexión, noción vinculada a la nueva museología. Según datos una evaluación de un programa que utiliza esta metodología, su punto de partida es "ser un instrumento para facilitar procesos de aprendizaje a distintos niveles y una herramienta para el desarrollo de las habilidades cognitivas de los alumnos" ${ }^{\prime 1}$. Sumado a esta finalidad, la propuesta

(...) facilita la mejora de capacidades deductivas, especulativas y argumentativas de los alumnos. Favorece la generación de interpretaciones basadas en las imágenes de menor a mayor complejidad. Permite la mejora de la expresión oral. Fomenta una nueva relación profesor-alumno, reafirmando el desarrollo personal del alumno ya que, al redefinir sus roles, se resituan en un plano de igualdad. Su objetivo principal es completar los objetivos del currículo y potenciar el aprendizaje activo frente a la recepción pasiva tradicional. Para su correcto funcionamiento se requiere que el profesor haga bien su papel de mediador y que tenga buena relación con los alumnos, también es necesario que haya una actitud receptiva por parte de los participantes y que las normas del método se apliquen correctamente (POU, 2002).

Como hemos mencionado anteriormente, los educadores son considerados los facilitadores del proceso, nunca la fuente principal de información u opinión. Por ello su tarea consiste en posibilitar que los estudiantes debatan distintas alternativas y dejan que el proceso conducido con las "Estrategias de Pen- 
samiento Visual" fortalezca su habilidad de examinar, articular y reflexionar.

El profesor desempeña el papel de moderador, sin aportar información u opinión algunas [sic]. El profesor permite que los alumnos discutan las diversas posibilidades y que el proceso de percepción mismo incremente su capacidad de analizar, relacionar, escuchar y reflexionar. La participación de los alumnos por turno fomenta la curiosidad y la búsqueda de información (VUE, 2001c).

De esta forma, el profesor o el educador del museo se convierte en el protagonista del hecho educativo. Si el profesor sabe las normas del método, es decir, sabe estructurar el diálogo, parafrasear a los alumnos para mejorar su expresión oral y conducir debates de interés común, ya están conseguidos los objetivos propuestos.

El currículo se aplicará de modo plenamente satisfactorio si el profesor sigue una serie de pautas básicas, lógicas y comprobadas científicamente, aunque al principio le parezcan algo restrictivas. Estas sencillas reglas abren todo un mundo de posibilidades (VUE, 2001c).

Sin embargo, queremos destacar que, a pesar de mostrar a los educadores como líderes del proceso de aprendizaje, su formación se relega a un segundo plano, ya que es entendida como meramente práctica ${ }^{12}$. Esto significa, en palabras de Padró, que la profesión del educador en los museos es comprendida según una concepción tradicional y artesana. Con ello nos referimos a que muchos departamentos de educación se consideran meramente prácticos, sin atender a una formación museológica y/o educativa específica. En esta tendencia se considera que la educación es más una vocación que una profesión y por tanto, el educador es visto como un didacta (PADRÓ, 2005).

A pesar de esto, es destacable que durante la práctica de V.T.S. se permita que los visitantes observen detenidamente las obras, se facilite la discusión y se estimule el pensamiento crítico y creativo.

El profesor considera las aportaciones de todos los alumnos para que se sientan respaldados e indica al grupo el valor de las ideas de cada persona. (...) Como parte del proceso de adquirir un pen- 
Replanteando las estrategias de pensamiento visual: un método controvertido para la educación en museos

samiento crítico, se necesita subrayar la importancia de considerar todas las posibilidades. Hay que mantenerse abierto mientras los alumnos aportan ideas y considerar todos los comentarios igualmente válidos (VUE, 2001c).

Sin embargo, la noción de pensamiento crítico a la que se refieren no incluye una reflexión por parte de los estudiantes o visitantes del proceso seguido, y tampoco se les ofrece el contexto social, cultural, religioso ni político de las obras. Por ello, desde nuestro punto de vista el tipo de pensamiento que se estimula, se trataría más de un pensamiento tolerante que de una postura crítica. Esto es debido a que fomenta que todos se expresen y valoren por igual las opiniones de los demás participantes, pero no se anima a que se pongan en tela de juicio las diferentes opiniones, incluyendo tanto las propias como las de compañeros, educadores o expertos que hablan sobre las obras.

Por estas razones, consideramos que V.T.S. puede ser adecuado como un método para utilizarse en un primer contacto con el arte, ya que sin duda, permite que todos los visitantes hablen, rompiendo con algunos mitos que encierra la idea tradicional de museo de centrarse en la contemplación de la obra en la búsqueda de una experiencia estética. Sin embargo, tras haber comentado formalmente la obra y haber satisfecho las necesidades de todos los participantes de hablar, consideramos que se deberían tratar temas candentes, polémicos y críticos.

Pero, contrario a esta postura, Yenawine aboga por que no se indague en temas no convencionales a la hora de establecer un diálogo frente a las imágenes, perdiéndose la oportunidad de abordar temas de actualidad.

Existen temas que, en general, deberán evitarse pues, a pesar de ser importantes o se presenten satisfactoriamente a un debate bajo ciertas circunstancias, las situaciones que presentan conllevan demasiadas variables para asegurar una experiencia positiva. Las imágenes que ilustran escenas de violencia, posturas políticas específicas, imaginería religiosa determinada, desnudez, sexualidad y sensualidad manifiestas, así como temas grotescos o macabros pueden perjudicar a los observadores inexpertos si los valores expresados en ellas entran en conflicto con los suyos propios (YENAWINE, 2001). 
De esta manera, al evitar cuestiones tales como la raza, el género o la clase social se pone en evidencia que V.T.S. no considera cómo las condiciones socioeconómicas afectan las vidas y expectativas de las personas.

\section{V.T.S. al descubierto: un repaso a sus limitaciones}

Teniendo en cuenta todo lo anteriormente citado, queremos evidenciar nuestra preocupación de que actualmente en España y otros países se trabaje la educación en los museos desde una visión esencialista principalmente. Nos preguntamos porqué se implementan métodos que -aunque camuflados tras un aparente diálogo abierto- son unidireccionales. Esto se materializa, por ejemplo, en el punto de partida tradicional que utiliza V.T.S., ya que la pregunta con la que se abre el diálogo es siempre: "¿qué ves?", cuestión que no favorece un pensamiento relacional ni crítico. Esta pregunta hace suponer que en la obra hay un contenido que los visitantes deben encontrar, una respuesta correcta que han de identificar. Además, se concibe que el visitante llega al museo sin ningún conocimiento previo y se parte de que aprender significa asimilar información y hechos que son independientes del sujeto. Esta perspectiva tiende hacia una posición conductista, concluyendo que el aprendizaje consiste en la suma de varias asociaciones simples y que todo lo que se conoce se ha adquirido a través de la experiencia (HEIN, 1998).

Por otro lado, V.T.S. tampoco explora formas de pensamiento que no estén sujetas a la noción moderna de racionalidad. Estas alternativas de pensamiento serían las que prestan atención a la intuición y al pensamiento no lineal y multilógico, donde el pensar es biográfico, contextual y no es sólo una actividad mental (HERNÁNDEZ, 2006). Asimismo, es importante destacar que, a pesar de que se utilice una metodología basada en la realización de múltiples preguntas, V.T.S. parte de que hay un conocimiento clave que se tiene que aprender. Por ello, a pesar de que se promueve la discusión en el grupo, siempre se incita a llegar a un consenso y a dejar claro cuál es el mensaje predeterminado que se debe asimilar. 
Replanteando las estrategias de pensamiento visual: un método controvertido para la educación en museos

V.T.S. es un proceso de descubrimiento. El debate se inicia mediante unas preguntas concretas, formuladas para provocar diversas respuestas con sentido, en función de lo que se ve en las imágenes. (...) Así los alumnos conocen la ambigüedad del arte y sus diversos y ocultos posibles significados. (...) La pregunta recomendada (y sus variaciones) les obliga a indagar en busca de un significado. (...) Con el tiempo, la interacción del grupo pondrá en su lugar a la 'verdad' (VUE, 2001c).

Además, a menudo, este mensaje tiene más que ver con las visiones que los museos fomentan del artista y con las expectativas que crean en los visitantes, que con las posibilidades de pensar en otras versiones que estos pueden aportar.

La mayor parte de sus interpretaciones coincidirán con el propósito del artista si se buscan las razones indagando en la imagen. (...) El hecho de que las imágenes sean accesibles ofrece a los observadores la oportunidad de descubrir por sí mismos los significados pretendidos por el artista. (...) Cuanto más abierta sea la interpretación de una obra, más acertadas podrán ser las opiniones intuitivas del observador, siempre y cuando se enmarquen dentro del propósito del artista o de la cultura en cuestión (VUE, 2001c).

Entonces, V.T.S. hace pensar que hay una verdad única en la obra que debe ser descifrada $y$, por tanto, no permite ningún descentramiento ni problematización, ni mucho menos establece conexión alguna con el sujeto y su mundo (HERNÁNDEZ, 2006). Debido al tipo de preguntas que se realizan durante las sesiones con V.T.S., la importancia se da exclusivamente a la obra con la que se está trabajando y, consecuentemente, al artista que la produjo. Los participantes -sus expectativas, sus circunstancias- quedan excluidos a la hora de llevar a cabo la interpretación de la obra, ya que se entiende que esta interpretación es única y se encuentra en la propia obra y nunca en los espectadores. Como afirma el teórico cultural Stuart Hall (1997), debemos enfatizar que no existe una simple o correcta respuesta a preguntas como '¿qué quiere decir esta imagen?', ya que los significados cambian en el tiempo y no hay leyes que garanticen el 'significado verdadero' de las cosas; por ello, no se debería establecer un debate entre quien tiene razón y 
quien está equivocado, sino entre significados e interpretaciones igualmente plausibles, aunque en ocasiones compitan y se contesten.

También es cierto que no sólo la pregunta inicial "¿qué ves?", sino también el resto de las cuestiones que facilitan el diálogo, priorizan el sentido de la vista, dejando de lado la posibilidad de experimentar o conocer el arte desde los otros sentidos. Por ello, los programas educativos basados en las "Estrategias de Pensamiento Visual", marginan a las personas que aprenden de forma no visual o verbal, ya que no suelen estar acompañados por una actividad que requiera la utilización de sentidos y habilidades distintas $^{13}$. En este sentido sería un programa "monoalfabetizador" y se distancia de las propuestas multialfabetizadoras actualmente vigentes (LANKSHEAR y KNOBEL, 2003).

Otra de las ideas fundamentales de V.T.S. es que el educando aprende mientras se expresa oralmente aunque todo ha sido previamente diseñado y decidido por los adultos ${ }^{14}$. Se da por sentado que los participantes aprenden desarrollando sus capacidades de pensamiento y razonamiento mediante programas bien estructurados (diseñados por expertos) de habilidades para aprender (HERNÁNDEZ, 2006).

Si nuestro deseo es que los participantes establezcan una relación sólida con el arte, deberíamos pensar en el tipo de arte más adecuado para iniciarlos en la materia. Si pretendemos, además, que aprendan a 'leerlo' por si mismos -que se conviertan en observadores autosuficientes- deberíamos pensar la mejor manera de estimular esta habilidad. (...) La contemplación del arte se enseña mejor alentando a los alumnos, ayudándoles a mirar con detenimiento, a pensar sobre lo que ven, y a articular sus reacciones (YENAWINE, 2001).

También consideramos cuestionable de este método educativo su peculiar manera de seleccionar las obras de arte "adecuadas" para los observadores. Existe una firme resistencia a incluir en las sesiones de V.T.S. la cultura audiovisual, obviando de este modo manifestaciones artísticas distintas a la pintura o escultura, -tales como videos, performances, instalaciones, publicidad, entre otros-. Al centrar las sesiones en observar obras artísticas realizadas con procesos tradicionales -es decir, pintu- 
Replanteando las estrategias de pensamiento visual: un método controvertido para la educación en museos

ra, escultura, dibujo y grabado-, se parte de una noción de arte elitista, ya que se potencia exclusivamente un acercamiento al arte que se considera culto, elevado y legitimado.

El proceso de selección de obras con el fin de iniciar a los observadores principiantes a las maravillas del arte es una tarea que debe hacerse a conciencia. (...) La pintura resulta muy útil, pues ha existido siempre en todas partes y a menudo ha sido considerada la más alta expresión artística de una cultura. (...) Las ilustraciones, la mayor parte del fotoperiodismo, los dibujos animados y los anuncios rara vez suponen una elección útil porque permiten pocas interpretaciones. Los temas con una gran carga, las técnicas experimentales, y los estilos provocadores pueden desviar a los observadores de este objetivo [animar a contemplar, a pensar y a desarrollar unas interpretaciones bien infundadas] (YENAWI$\mathrm{NE}, 2001)$.

Así, para elegir las imágenes adecuadas para que los "principiantes, mediante la práctica, elaboren su propio entendimiento del arte incrementando su potencial como observadores", se recomienda a los educadores seguir unas rigurosas pautas ideadas por Philip Yenawine (2001). Según estas normas, las imágenes seleccionadas tienen que ser reconocibles, reales y deben siempre contar una historia. En este sentido, se sugiere que sean paisajes, retratos o escenas "de género" (juegos, familia, actividades laborales) y cuya lectura sea fácil de desentrañar para que cautiven a todo tipo de público. Respecto a las técnicas, las que más se recomiendan son la pintura, la escultura figurativa, las reproducciones de dibujos y estampas, y la fotografía. Así, se excluye no sólo toda la pintura abstracta sino también casi todas las manifestaciones artísticas posteriores a las primeras vanguardias, ya que a partir de este momento histórico la pintura rompe con la imitación a la realidad. Por otro lado, se considera importante que se conozca la intención del artista o la cultura que ha elaborado la pieza para no caer en malas interpretaciones.

Si desconocemos el propósito del artista o la cultura en la que se enmarca, este tipo de arte nos resultará ajeno, y nuestra comprensión del mismo será limitada, susceptible de ser malinterpretada (YENAWINE, 2001). 
Sin embargo, partiendo de que no hay una verdad única en la obra, sino que el espectador la interpreta según su bagaje y circunstancias, una obra nunca podrá ser malinterpretada. Finalmente, también se hace hincapié en el tipo de obras que se deben evitar, como las que requieran una información especializada o aquellas cuyo significado esté determinado por un artista o cultura concretos (dentro de esta categoría se incluyen temas históricos, religiosos, mitológicos, y especialmente étnicos). Tampoco son adecuadas las escenas de violencia, política, religión, desnudez, sensualidad o sexualidad, los temas grotescos o macabros y las naturalezas muertas (porque presentan una serie de cualidades que, al igual que la pintura abstracta, no invitan a investigar) (YENAWINE, 2001). Siguiendo estas pautas de selección, siempre se elegirán imágenes cuyo análisis difícilmente trascenderá los aspectos estéticos y formales. En este sentido, notamos que no permiten el tratamiento de ningún tema controvertido ni conectado con la realidad sociocultural que los participantes puedan estar viviendo. Desde nuestro punto de vista, para conocer las obras de arte y analizarlas en contexto, tendríamos que aprender sobre sus sistemas de producción, mecenazgo, canales de distribución, ideas expresadas por artistas, coleccionistas y críticos, y todos aquellos elementos que crean el sistema del arte (EFLAND, FREEDMAN y STUHR, 2003).

\section{Reflexiones inacabadas}

Partiendo de que la situación actual de la educación en los museos es de tránsito, y muchos de ellos se encuentran en un proceso de cambio y replanteamiento de su ideología educativa, es lógico que traten de buscar orientación y referencias en tendencias de otros países. Sin embargo, hemos observado que más que ideas o referentes, lo que se prefiere es la adopción de un determinado método educativo, con criterios teóricos bien definidos y pautas para su implementación claras; en fin, un método que pueda utilizarse con facilidad y aprenderse rápidamente. Sin embargo, no se considera que cualquier metodología educativa es creada en un momento y lugar determinados $y$, 
Replanteando las estrategias de pensamiento visual: un método controvertido para la educación en museos

consecuentemente, permanece siempre ligada a circunstancias socioculturales concretas. Por ello, a la hora de implementar V.T.S. en cualquier institución no se debería olvidar su contextualización y adaptación a los intereses locales. En contraste con esta idea, Yenawine (2001) afirma que no hace falta ninguna adaptación de este método previa a su implementación en cualquier contexto.

- Ha sido necesario algún proceso de adaptación del programa VTS para poder ser aplicado a un medio como éste, tan distinto de Estados Unidos?

- De acuerdo con nuestra experiencia, no. No ha habido necesidad de introducir nuevas variables a la hora de aplicar en este contexto nuestro proceso de facilitar la discusión que es la clave del método de enseñanza del VTS (GONZÁLEZ, 2006).

Creemos que para justificar la adopción de V.T.S. en los museos, se valora que a partir de él pueden desarrollarse programas educativos atractivos, que posibiliten la llegada de más público a la institución, cometido normalmente asumido por los departamentos de educación. Por estos motivos, se accede a la implementación de este método sin cuestionar sus contenidos y sin reflexionar sobre el tipo de visitante que se está creando. A este respecto, Yenawine comenta en una reciente entrevista:

Los educadores de museos de todos los países en los que hemos trabajado están interesados en el VTS por los mismos motivos: EI VTS dinamiza y da vida a los programas pedagógicos de los museos. El trabajo de investigación que hay detrás del VTS - que corrobora el crecimiento tanto en términos de observación como de habilidades interpretativas por parte de los distintos públicos ha producido un considerable eco entre todos los profesionales de museos interesados en provocar un impacto sobre los visitantes (GONZÁLEZ, 2006).

Sin embargo, en la actualidad, la educación museística ya no se entiende sólo como un proceso lineal en el que el museo le enseña un contenido al visitante, sino que trata más bien de cómo los visitantes usan el museo de maneras significativas para ellos (ROBERTS, 1997); por eso, la esencia de la educación 
hoy en día es crear conocimiento y posibilitar la construcción de significados.

La educación en el museo es concebida como un conjunto de procesos, educación como forma de vida, como algo deseable para asimilar los acontecimientos diarios y como actitud positiva frente al mundo. Además los museos son las únicas instituciones de la sociedad que pueden satisfacer las necesidades de aprender de todo tipo de personas. Son también forma de ocio pero siempre en relación con aprendizaje. Los visitantes esperan cada vez más que una visita a un museo tenga una importancia personal inmediata, interactiva y que dé lugar a la adquisición clara e identificada de conocimientos. La educación en el museo se entiende cada vez más como la fuerza que da forma y que se encuentra detrás de la política y de los objetivos generales del museo (HOOPERGREENHILL, 1998).

De este modo, la educación en el museo no es concebida ya sólo ocio o diversión, sino que es entendida como un acto de reflexión y de creación de nuevas narrativas igualmente válidas y significativas que la propuesta por la propia institución. Estas narrativas alternativas parten de los propios visitantes que, motivados por el educador, construyen sus propias historias teniendo en cuenta su conocimiento previo, sus experiencias y sus condiciones sociales y biográficas (ROBERTS, 1997). Debemos tener en cuenta, por tanto, que un visitante en un museo percibe de manera inteligente, y que cada uno tiene sus experiencias, expectativas, opiniones, suposiciones. De este modo, se puede decir que el proceso de percepción no es algo ligado exclusivamente a los sentidos, sino que implica un proceso activo por parte del sujeto que lo puede conectar con su "sentido de ser". Siempre percibimos desde lo que sabemos; no extraemos del medio toda la información, sino aquellos indicios coherentes con nuestras hipótesis, con lo construido a partir de experiencias previas y de acuerdo a un proyecto o interés cognitivo (DÍAZ y UNZU, 2003). Consecuentemente, "el museo tiene que proporcionar al visitante herramientas para interactuar considerando que cada uno posee sus propios conocimientos, valores y sentimientos intransferibles" (PADRÒ, 1995, p. 19). Por todo ello, no es aceptable la concepción de aprendizaje conductista fomentada desde V.T.S., que considera que la mente del visi- 
tante es una "tabula rasa" y que aprender significa simplemente sumar asociaciones simples (HEIN, 1998).

Por el contrario, consideramos que la educación museística debe construirse de un modo indagador y crítico; desde esta posición, métodos educativos como V.T.S. deberían ser reformulados, ya que en vez de promover la reflexión y el aprendizaje significativo en el visitante, siguen reproduciendo formas tradicionales de educación. Para romper con ello, entre otros factores, sería necesario repensar la formación y función de los educadores que llevan a cabo el proceso educativo. En este sentido, es importante promover en ellos la indagación sobre su trabajo y estimular su capacidad crítica a través de una formación continua. Éste sería el primer paso para que se convirtieran en profesionales reflexivos concebidos, no como consumidores de los conocimientos producidos por otros, sino como creadores de conocimiento en relación con la enseñanza y el aprendizaje (SCHÖN, 1998).

Desde nuestra postura como investigadoras en el campo de la educación en los museos, consideramos necesario promover estrategias de resistencia y acción que permitan reposicionar las formas hegemónicas de educación y posibilitar espacios para el cuestionamiento. Nuestro objetivo es fomentar que se lleven a cabo prácticas educativas en los museos que inciten a los visitantes a interrogarse, y desde las que se asuma que el conocimiento que se construya ayudará a las personas a ser mejores y a vivir más plenamente más allá del mundo académico (HOOKS, 1994).

Gracias a la Dra. Carla Padró, al Dr. Fernando Hernández y a todas las personas que nos ayudaron a construir, deconstruir y reconstruir este texto. 


\section{Notas}

1- A pesar de que en su origen este método se dio a conocer como V.T.C. (Visual Thinking Curriculum), en la actualidad se difunde con las siglas V.T.S. (Visual Thinking Strategies) y, por ello, a lo largo del artículo nos referiremos al método de este modo.

2- Según Carla Padró, "La mayoría de departamentos educativos [de museos] sin tener muy claras sus teorías implícitas fruto de un trabajo que, durante mucho tiempo, ha sido considerado de traducción del discurso oficial o, en los últimos años, de reproducción del currículum escolar" en Padró, C. 2005: Museos y educación artística: redes de paso, encrucijadas difusas, zonas de viraje (Texto sin publicar).

3- Paralelamente a este estudio, Michael Parsons en la Universidad de Ohio, siguiendo también el modelo de desarrollo propuesto por Piaget, llegaba a las mismas conclusiones: para comprender la realidad del museo se necesitaba una formación en educación artística que tuviera en cuenta los estadios del desarrollo del juicio estético.

4- Véanse los programas "Mira!" del Caixafòrum de Barcelona (España) o "D.A.P., Didáctica del Arte y del Patrimonio" -que usa las estrategias de Pensamiento Visual-, comercializado por la Fundación Arte Viva en España, Argentina, Brasil y otros países.

5- El constructivismo sostiene que el conocimiento es resultado de un proceso dinámico e interactivo durante el cual la información es interpretada y reinterpretada por la mente, que va construyendo progresivamente modelos explicativos cada vez más complejos y potentes. Esto significa que conocemos la realidad a través de los modelos que construimos para explicarla, y que estos modelos siempre son susceptibles de ser mejorados o cambiados (Coll y Gómez, 1995).

6- Según Piaget, "los niños atraviesan unas etapas o estadios cualitativamente distintos que denomina: sensoriomotriz, preoperacional, operacional concreto y operacional formal" (Agirre, 2000: 54).

7- Para profundizar en el constructivismo crítico, ver: Hernández, F. (2000) Educación y cultura visual. Barcelona: Octaedro, pgs. 108-109

8- Para profundizar en los estadios de Parsons y en los de Housen, consultar: Hernández, F. 2000: La investigación sobre la comprensión: la interpretación como clave de la educación escolar. En: Educación y Cultura Visual (págs. 105-132) Barcelona, Octaedro.

9- "Estrategias de Pensamiento Visual" es la traducción literal al castellano de "Visual Thinking Strategies" o V.T.S. Utilizamos el término V.T.S. cuando nos referimos al método en general, y "Estrategias de Pensamiento Visual" al hablar de las metodologías que se utilizan.

10- Esta idea de que es posible leer una imagen del mismo modo que un texto es actualmente de uso corriente para los defensores de V.T.S. Por ejemplo, en la página web del Museo Picasso de Málaga (España) podemos leer: "Primavera 2006.Curso para profesores de Primaria basado en las Estrategias de Pensamiento Visual (V.T.S.): Se plantea trabajar con los alumnos para aprender a mirar (al igual que aprendemos a leer) como parte de un proceso de desarrollo del conocimiento basado en el hecho mismo de mirar y tratar de comunicarlo por medio de la palabra y dentro de una discusión abierta del grupo."

11- La evaluación citada se refiere a: Pou, C. 2002: El programa educativo "Mira!" del Laboratori de les Arts: un instrumento para la escuela primaria. (Texto sin publicar. Investigación financiada por la Fundació "la Caixa")

12- "El educador de V.T.S. hará mejor su trabajo cuantas más veces lo haga. Es un método que se va aprendiendo con la práctica" (Linda Duke, durante su conferencia en las XIII Jornadas de los D.E.A.C., Murcia, octubre de 2005)

13- En 1983 Howard Gardner publicó su libro "Frames of Mind: The theory of multiple 
Replanteando las estrategias de pensamiento visual: un método controvertido para la educación en museos

intelligences", en el que plantea una visión pluralista de la inteligencia, reconociendo en ella muchas facetas diferentes, entendiéndose así que cada persona posee distintos potenciales cognitivos. De esto se deriva que no todas las personas aprenden del mismo modo ya que todos desarrollamos nuestras inteligencias de formas dispares. Esta idea debería tenerse en cuenta a la hora de plantear cualquier actividad educativa.

14- Análogamente al método educativo conocido como "learning by doing", podríamos considerar al V.T.S. como un método que propone el "learning by telling", ya que considera que el niño aprende cuando se expresa y, por lo tanto, fomenta exclusivamente su expresión oral.

\section{Referências Bibliográficas}

AGIRRE, I. Teorías y prácticas en educación artística. Ideas para una revisión pragmatista de la experiencia estética. Pamplona: Universidad Pública de Navarra, 2000.

BELTRÁN, C. L. La educación artística en centros de arte contemporáneo: una alternativa para la construcción de aprendizajes. En: Huerta, R. y De La Calle, R. (eds.) La mirada inquieta. Educación artística y museo. Valencia: PUV, 2005, p. 169-182.

COLL, C. y Gómez-Granell, C. De qué hablamos cuando hablamos de constructivismo. Cuadernos de Pedagogía (221), 8-10, 1995.

DíAZ, I. y Unzu, A. La mirada que construye. Competencias y extravíos.

En: Lorente, J.P. y ALMAZÁN, D. Museología crítica y arte contemporáneo. Zaragoza: Universidad de Zaragoza, 2003, p. 185-201.

DUNCAN, C. Civilizing rituals. London, Routledge, 1995.

EFLAND, A., FREEDMAN, K. y STUHR, P. [1996] La educación en el arte posmoderno. Barcelona: Paidós, 2003.

GARDNER, H. Frames of Mind: the theory of multiple intelligences. New York: Basic Books, 1983.

GOODSON, I. [1997] El cambio en el currículum. Barcelona: Octaedro, 2000.

GONZÁLEZ, F. Estrategias de Pensamiento Visual. Contemporánea. Revista grancanaria de cultura (1), 2006.

HALL, S. (Ed.) Representation: cultural representations ans signifying practices. Milton Kynes: Open University, 1997.

HARGREAVES, D.J. Infancia y educación artística. Madrid: Morata, 1991. 
HEIN, G.E. Learning in the museum. New York, Routledge, 1998

HERNÁNDEZ, F. Educación y cultura visual. Barcelona, Octaedro, 2000. 2006.

HOOKS, B. Teaching to transgress: education as the practice of freedom. New York: Routledge, 1994.

HOOPER-GREENHILL, E. [1994] Los museos y sus visitantes. Gijón, TREA, 1998.

LANKSHEAR, L. \& KNOBEL, M. New Literacies. Changing knowledge and classroom learning. Buckingham: Open University Press, 2003.

MACDONALD, S. (Ed.) The politics of display: museums, science, culture. London, Routledge, 1998.

MACHÍN, M.F. Museo Picasso de Antibes y Artium de Vitoria-Gasteiz. Dos museos, dos proyectos educativos. En: CALAF, R. y FONTAL, O. Comunicación educativa del patrimonio: referentes, modelos y ejemplos. Gijón: Trea, 2004, p. 179-199.

MORALES, J.J. La evaluación en el área de educación visual y plástica en la E.S.O. (tesis doctoral, Universitat Autónoma de Barcelona), 2001.

PADRÓ, C. ¿Lecciones o preguntas? La relación entre el visitante y el proceso expositivo en la museología estadounidense contemporánea. Revista de museología (6), 19-22, 1995.

PADRÓ, C. Educación artística en museos y centros de arte. En HUERTA, R. y DE LA CALLE, R. (eds.) La mirada inquieta. Educación artística y museos. Valencia: PUV, 2005, p. 137-152.

PARSONS, M. [1987] Cómo entendemos el arte. Una experiencia cognitivo-evolutiva de la experiencia estética. Barcelona: Paidós, 2002.

PASTOR, I. Pedagogía museística. Nuevas perspectivas y tendencias actuales. Barcelona: Ariel Patrimonio, 2004.

POU, C. El programa educativo 'Mira!' del Laboratori de les Arts: un instrumento para la escuela primaria, 2002 (Texto sin publicar, investigación financiada por la Fundació "la Caixa").

ROBERTS, L. From knowledge to narrative. Educators and the changing museum. Washington y Londres, Smithsonian Institution Press, 1997.

SCHÖN, D. El profesional reflexivo. Cómo piensan los profesionales cuando actúan. Barcelona, Paidós, 1998.

VUE. Background and History, VUE, 2001a. En: www.vue.org (última consulta: abril 2006)

VUE. Understanding the Basics, VUE, 2001b. En: www.vue.org (última consulta: abril 2006)

VUE. Comprendiendo los conceptos básicos de VTS, 2001c (Texto divulga- 
Replanteando las estrategias de pensamiento visual: un método controvertido para la educación en museos

do y utilizado por VUE en el curso "VTS Estrategias de Pensamiento Visual" en el Centro Atlántico de Arte Moderno de Las Palmas de Gran Canaria, 15-18 de Noviembre de 2005).

VUE. Un vistazo al VTS, 2001d. (Texto divulgado y utilizado por VUE en el curso "VTS Estrategias de Pensamiento Visual" en el Centro Atlántico de Arte Moderno de Las Palmas de Gran Canaria, 15-18 de Noviembre de 2005).

VYGOTSKY, L. Mind in society: the development of higher psychological processes. Cambridge: Harvard University Press, 1978.

YENAWINE, P. Iniciación al arte: ideas para la selección de imágenes, 2001 (Texto divulgado y utilizado por VUE en el curso "VTS Estrategias de Pensamiento Visual" en el Centro Atlántico de Arte Moderno de Las Palmas de Gran Canaria, 15-18 de Noviembre de 2005).

\section{Páginas web}

Artium, Centro-Museo Vasco de Arte Contemporáneo de Vitoria:

$<$ http://www.artium.org>

Caixafòrum de Barcelona: <http://www.fundacio.lacaixa.es/caixaforum> Centro Atlántico de Arte Moderno de Las Palmas de Gran Canaria: $<$ http://www.caam.net>

Museum of Modern Art de Nueva York: <http://www.moma.org> Museo Picasso de Málaga: <http://www.museopicassomalaga.org> Visual Understanding in Education: <http://www.vue.org>

\section{ENERITZ LÓPEZ}

Investigadora en formación, Universidad de Barcelona. Financiación: Gobierno Vasco. Email: eneritzlop@hotmail.com

\section{MAGALI KIVATINETZ}

Becaria de investigación, Universidad de Barcelona. Coordinadora de motiVART serveis educatius. Email: maga@motivart.com 